\title{
Peripheral Arterial Disease among Patient Undergoing Maintenance Hemodialysis in Dakar (Senegal)
}

\author{
Habin Yabama Aida Lengani ${ }^{*}$, Mouhamadou Moustapha Cissé2, Hamadoun Yattara ${ }^{3}$, \\ Alassane Mbaye ${ }^{4}$, Gérard Coulibaly ${ }^{1}$, Joseph Salvador Mingou ${ }^{4}$, El Hadj Fary Ka², \\ Abdou Niang ${ }^{2}$, Abdoul Kane ${ }^{5}$, Boucar Diouf ${ }^{2}$
}

\author{
${ }^{1}$ Departement of Nephrology, University Hospital Yalgado Ouédraogo, Ouagadougou, Burkina Faso \\ ${ }^{2}$ Departement of Nephrology, University Hospital Aristide le Dantec, Dakar, Sénégal \\ ${ }^{3}$ Departement of Nephrology, University Hospital of Point G, Bamako, Mali \\ ${ }^{4}$ Departement of Cardiology, National Hospital Grand Yoff, Dakar, Sénégal \\ ${ }^{5}$ Cheikh Anta Diop University, Dakar, Sénégal \\ Email: *aidalengani@yahoo.fr
}

How to cite this paper: Lengani, H.Y.A., Cissé, M.M., Yattara, H., Mbaye, A., Coulibaly, G., Mingou, J.S., Ka, E.H.F., Niang, A., Kane, A. and Diouf, B. (2021) Peripheral Arterial Disease among Patient Undergoing Maintenance Hemodialysis in Dakar (Senegal). Open Journal of Nephrology, 11, 242-251.

https://doi.org/10.4236/ojneph.2021.112019

Received: February 26, 2021

Accepted: May 24, 2021

Published: May 27, 2021

Copyright $\odot 2021$ by author(s) and Scientific Research Publishing Inc. This work is licensed under the Creative Commons Attribution International License (CC BY 4.0).

http://creativecommons.org/licenses/by/4.0/

\section{(c) (i) Open Access}

\begin{abstract}
Background: Peripheral arterial disease (PAD) is common in patients with chronic kidney disease (CKD). It is a surrogate marker of generalized atherosclerosis. In sub-Saharan Africa, PAD remains understudied in CKD. Ankle-brachial index (ABI) is a non-invasive and cost-effective tool to diagnose PAD. Objectives: Our aim was to determine the prevalence and associated risk factors for PAD in hemodialysis patients. Patients and Methods: We conducted a cross-sectional study from July 1 to December 31, 2012 in the department of Nephrology of the University Hospital Aristide le Dantec of Dakar. All consenting patients, aged above 18 years, on hemodialysis for at least 6 months were included. ABI measurements were performed using a handled pulse doppler. PAD was defined as an ABI of $<0.9$ or the history of surgical revascularization and/or amputation due to vascular disease. The patients were divided into two groups according to the presence or not of PAD. Standard blood tests and anthropometrical parameters were recorded. Results: A total of 53 patients with a mean age of $49.15 \pm 15.18$ were included. The sex ratio was 0.70 . Hypertension (83.01\%), low HDL-cholesterol (26.41\%) and cigarette smoking $(20.75 \%)$ were the main cardiovascular risk factors. Prevalence of PAD was $47.16 \%$. Among patients with PAD, 52\% had no suggestive symptoms. Lower pre-dialysis $(\mathrm{p}=0.0384)$ and post-dialysis $(\mathrm{p}=$ 0.0447) diastolic blood pressure (BP) were significantly associated with PAD. The conventional risk factors (tobacco consumption, diabetes, alcohol consumption, dyslipidemia, hypertension, age), iPTH and CRP levels were not
\end{abstract}


correlated with PAD. Conclusion: PAD is common among patients undergoing maintenance hemodialysis in Senegal. Early diagnosis and management of PAD should be routinely performed in CKD patients.

\section{Keywords}

Ankle Brachial Index, Peripheral Arterial Disease, Hemodialysis

\section{Introduction}

Peripheral arterial disease (PAD) refers to stenosis or occlusion of the arteries of the lower limbs. It is a marker of generalized atherosclerosis. PAD is common in patients with chronic kidney disease (CKD) [1] [2]. The high prevalence of traditional cardiovascular risk factors such as hypertension (HTN), diabetes mellitus, tobacco use, dyslipidemia, age and the existence of uremia-related cardiovascular risk factors are responsible for an accelerated atherosclerosis in CKD [1]. Ankle brachial index (ABI) is a simple, non-invasive method to diagnose $\mathrm{PAD}$. In comparison to angiography, the gold standard for detecting atherosclerosis in the lower limbs arteries, low ABI $(<0.9)$ has good sensitivity (between $69 \%$ and $79 \%$ ) and excellent specificity (between $83 \%$ to $99 \%$ ) [3]. PAD is associated with increased cardiovascular and overall morbidity and deaths in the general population and among hemodialysis patients [4] [5]. In a study by Ono et al. [5], the risk for cardiovascular mortality was 5.9-fold higher in dialysis patients with low ABI $(<0.9)$.

PAD remains one of the least studied atherosclerosis markers. Yet, it is the most common manifestation of atheromatous cardiovascular disease compared to coronary artery disease and ischemic stroke in patients with CKD [6]. ABI testing can help in early detection of PAD and for monitoring PAD's progression, which may improve patient's survival. There are little data on PAD in hemodialysis patients in sub-Saharan Africa. The aim of this study was to determine the prevalence of PAD in chronic hemodialysis patients and to study its relationship with some cardiovascular risk factors (CVRF).

\section{Patients and Methods}

\subsection{Patients and Study Design}

This cross-sectional study was conducted for 6 months, from 1 July to 31 December 2012, in nephrology department of the University Hospital Aristide Le Dantec (CHU-ALD) of Dakar (Senegal). We included all patients aged 18 and over, on maintenance hemodialysis for at least 6 months, who consent to participate in the study. Subjects who had bilateral amputation of lower limbs, bilateral arteriovenous fistula or with atrial fibrillation were not included [7].

\subsection{Anthropometry and Blood Pressure}

Socio-demographic characteristics, co-morbid conditions, behavioral measures 
(smoking history, alcohol consumption), clinical and biological data were noted.

Current smokers were defined as patients who currently smoked and had smoked more than 100 cigarettes in their lifetimes [8]. Former smokers were defined as patients who smoked more than 100 cigarettes in their lifetimes in the past [8].

Alcohol drinking was defined as consuming at least one beverage containing alcohol each week over the previous year [8]. Anthropometric measures included weight and height.

Body mass index (BMI) was calculated by dividing "dry" weight in kilograms by the square of height in meters. Predialysis and postdialysis systolic and diastolic blood pressure (BP) were measured in seated patients by qualified medical staff on the non-carrier arm of the arteriovenous fistula after at least a $5 \mathrm{mi}$ nutes rest. The systolic BP and diastolic BP considered were the respective calculated average systolic BP and diastolic BP of the month prior to data collection for each patient. Mean arterial pressure (MAP) was calculated based on the formula $\mathrm{MAP}=$ diastolic $\mathrm{BP}+1 / 3$ (systolic $\mathrm{BP}-$ diastolic $\mathrm{BP}$ ) and the pulse pressure $(\mathrm{PP})$ using the formula $\mathrm{PP}=$ systolic $\mathrm{BP}$ - diastolic BP. Hypertension (HTN) was defined as systolic blood pressure $\geq 140 \mathrm{mmHg}$ and/or diastolic blood pressure $\geq 90 \mathrm{mmHg}$, or the current use of antihypertensive medication [8].

\subsection{Laboratory Parameters}

Blood tests including hemoglobin level, hematocrit, white blood cell counts, serum albumin, urea nitrogen, creatinine, glucose, calcium, phosphate, intact parathyroid hormone (iPTH), sodium, potassium, total cholesterol, high-density lipoprotein cholesterol (HDL-cholesterol), low-density lipoprotein cholesterol (LDL-cholesterol), triglycerides, $\mathrm{C}$ reactive protein (CRP)) were performed using standard laboratory methods. The total cholesterol to high-density lipoprotein cholesterol (HDL-C) ratio was calculated.

Diabetes was defined as fasting glucose $\geq 1.26 \mathrm{~g} / \mathrm{l}$ or random blood glucose $\geq 2$ $\mathrm{g} / \mathrm{l}$, and/or the use of insulin or oral hypoglycemic agents [8].

Blood urea nitrogen measured before hemodialysis session $\left(C_{0}\right)$ and after hemodialysis session $\left(C_{t}\right)$ was used to calculate the urea reduction ratio (URR) [9]: $\mathrm{URR}=\left(C_{0}-C_{t}\right) / C_{O}$. In hemodialysis patients, $\mathrm{URR} \geq 65 \%$ and $\mathrm{Kt} / \mathrm{V} \geq 1.2$ indicates adequate minimum $\mathrm{HD}$ and $\mathrm{URR} \geq 70 \%$ and $\mathrm{Kt} / \mathrm{V} \geq 1.4$ indicates adequate optimal HD [9].

\subsection{ABI Measurement}

ABI measurement was conducted the day after hemodialysis session, by the same trained physician to eliminate interobserver variability. ABI was determined using a sphygmomanometer and a manual Doppler (Hadeco, ES-100V3, Kawasaki, Japan) with an $8 \mathrm{MHz}$ probe. After a rest period of 5 to 15 minutes in the supine position, the patient's systolic BP was registered in posterior tibial artery and dorsalis pedis artery of the right and left lower limb, and in the brachial artery of 
the arm without arteriovenous fistula. The sphygmomanometer cuff above the ankle was inflated to $20 \mathrm{mmHg}$ after the disappearance of the Doppler signal, and then deflated very slowly until it reappeared. The value of the pressure in $\mathrm{mmHg}$ at the time of the reappearance of the Doppler signal was noted as the systolic pressure of the recorded artery. ABI was calculated by the ratio of the lower value of the ankle systolic pressure divided by the systolic pressure of the arm without the dialysis blood access [5] [10] [11].

ABI was normal when between 0.9 and 1.4 [3]. It was considered low when it was below 0.9 [3]. PAD was defined by the history of surgical revascularization and/or amputation of limb, and/or ABI $<0.9[12]$.

\subsection{Dialysis Parameters}

The majority of patients underwent their routine hemodialysis sessions 3 times a week using a Fresenius $4008 \mathrm{~S}$ machine. Each hemodialysis session was performed for 4 hours using a polysulfone dialysis membrane. The flow rate of the dialysate was $500 \mathrm{ml} / \mathrm{min}$ and the blood flow was variable (between 250 and 350 $\mathrm{mL} / \mathrm{min}$ ). Anticoagulation of the extracorporeal circuit was performed with low molecular weight heparin for all patients.

\subsection{Statistical Analysis}

Statistical analyses were performed with SPSS (Statistical Package for Social Science), version 16.0. Continuous variables were expressed as mean \pm standard deviation (SD) and categorical variables, in count and percentage (\%). For comparison of patients with or without PAD, Stutent's $t$ test was used to compare mean values and $\mathrm{Chi}^{2}$ test was used to compare difference in prevalence rates. $\mathrm{p}$-value $<0.05$ was considered significant.

\section{Results}

\subsection{General Characteristics of the Study Population}

Table 1 shows the distribution of demographic characteristics, clinical, and laboratory parameters for the entire study population and for patients with and without PAD.

Fifty-three patients, with a mean age of $49.15 \pm 15.18$ (18 - 81 years) were included in the study. There were 22 men (41.5\%) and 31 women (58.5\%). Forty-four patients ( $83 \%)$ were hypertensive, 11 (20.75\%) were former smokers with an average consumption of $14.35 \pm 17.13$ packs/years, and 2 (3.8\%) patients were diabetic. None of patients drank alcohol. Four patients (7.5\%) had a history of stroke. The etiologies of ESRD were hypertension (51\%), glomerulonephritis $(15 \%)$ and polycystic kidney disease (7.5\%). The mean duration in hemodialysis was $4.24 \pm 2.89$ years $(0.91-12.91$ years). The mean interdialytic weight gain was $2.10 \pm 0.80 \mathrm{Kg}(0.145-4.16 \mathrm{Kg})$. Dialysis sessions were twice a week for 5 (9.4\%) patients who had an average interdialytic weight gain of $2.64 \pm 0.68 \mathrm{Kg}$ $(1.56-3.35 \mathrm{Kg})$. URR and $\mathrm{Kt} / \mathrm{V}$ were low in respectively 2 (3.8\%) and $6(11.32 \%)$ patients. 
Table 1. Comparison of baseline and clinical characteristics of patients with PAD and without PAD.

\begin{tabular}{|c|c|c|c|}
\hline \multirow{2}{*}{ Characteristics } & \multicolumn{3}{|c|}{ Peripheral arterial disease } \\
\hline & Yes $(n=25)$ & No $(\mathrm{n}=28)$ & $\mathrm{p}$-value \\
\hline Age (years) & $52.52 \pm 15.08$ & $46.14 \pm 14.89$ & 0.1278 \\
\hline Female gender (\%) & $16(64 \%)$ & $15(53.6 \%)$ & 0.2209 \\
\hline Duration of dialysis (years) & $4.15 \pm 2.38$ & $4.32 \pm 3.33$ & 0.8334 \\
\hline Diabetes & $1(4 \%)$ & $1(3.57 \%)$ & 0.4674 \\
\hline Stroke & $2(8 \%)$ & $2(7.15 \%)$ & 0.4165 \\
\hline Coronary artery disease & 0 & $1(3.57 \%)$ & - \\
\hline \multicolumn{4}{|l|}{ Cause of ESRD (\%) } \\
\hline Hypertension & $13(52 \%)$ & $14(50 \%)$ & 0.4422 \\
\hline Glomerulonephritis & $3(12 \%)$ & $5(17.85 \%)$ & 0.2761 \\
\hline Polycystic kidney disease & $1(4 \%)$ & $3(10.7 \%)$ & 0.1778 \\
\hline Diabetes mellitus & $1(4 \%)$ & 0 & - \\
\hline Others diagnoses & $2(8 \%)$ & $4(14.3 \%)$ & 0.2572 \\
\hline Unknown & $5(20 \%)$ & $2(7.15 \%)$ & 0.1004 \\
\hline Height $(\mathrm{cm})$ & $168.12 \pm 10.12$ & $170.17 \pm 8.63$ & 0.4298 \\
\hline Weight (Kg) & $62.54 \pm 15$ & $61.60 \pm 13.87$ & 0.8136 \\
\hline BMI $\left(\mathrm{kg} / \mathrm{m}^{2}\right)$ & $21.88 \pm 3.75$ & $21.10 \pm 3.66$ & 0.4474 \\
\hline Inter-dialytic weight gain (Kg) & $2.08 \pm 0.88$ & $2.31 \pm 0.72$ & 0.3006 \\
\hline \multicolumn{4}{|l|}{ Smoking status } \\
\hline Current smoker (\%) & 0 & 0 & - \\
\hline Former smokers (\%) & $6(24 \%)$ & $5(17.85 \%)$ & 0.3012 \\
\hline Tobacco (packs/year) & $14.5 \pm 20.91$ & $14.2 \pm 14.93$ & 0.9792 \\
\hline \multicolumn{4}{|l|}{ Pre-dialysis blood pressure (mmHg) } \\
\hline Systolic BP & $137.76 \pm 19.08$ & $142.07 \pm 19.84$ & 0.4252 \\
\hline Diastolic BP & $78.12 \pm 11.04$ & $84.39 \pm 10.43$ & 0.0384 \\
\hline $\mathrm{PP}$ & $59.64 \pm 14.86$ & $57.67 \pm 12.61$ & 0.6039 \\
\hline MAP & $97.96 \pm 12.46$ & $103.64 \pm 13.01$ & 0.1117 \\
\hline \multicolumn{4}{|l|}{ Post-dialysis blood pressure (mmHg) } \\
\hline Systolic BP & $135.12 \pm 21.76$ & $141.67 \pm 23.29$ & 0.2968 \\
\hline Diastolic BP & $75.44 \pm 10.18$ & $81.96 \pm 12.58$ & 0.0447 \\
\hline $\mathrm{PP}$ & $59.68 \pm 16.36$ & $59.71 \pm 14.63$ & 0.9944 \\
\hline MAP & $95.32 \pm 13.01$ & $101.89 \pm 15.44$ & 0.1022 \\
\hline \multicolumn{4}{|l|}{ Antihypertensive medications, n (\%) } \\
\hline RAAS blockers use & $21(75 \%)$ & $20(80 \%)$ & 0.3321 \\
\hline Calcium channel blocker use & $12(48 \%)$ & $15(53.6 \%)$ & 0.3484 \\
\hline$\beta$-blockers use & $14(50 \%)$ & $14(56 \%)$ & 0.3373 \\
\hline Statins use & $7(28 \%)$ & $6(21.43 \%)$ & 0.2986 \\
\hline Aspirin use & $5(20 \%)$ & $7(25 \%)$ & 0.3417 \\
\hline ABI & $0.78 \pm 0.08$ & $1.06 \pm 0.10$ & $<0.0001$ \\
\hline
\end{tabular}

ABI: ankle-brachial index; BMI: body mass index; BP: blood pressure; ESRD: end stage renal disease; MAP: mean arterial pressure; PP: pulse pressure; RAAS: renin-angiotensin-aldosterone system. 


\subsection{PAD Prevalence and Associated Factors}

The mean ABI was $0.92 \pm 0.17(0.51-1.3)$. The prevalence of PAD was $47.16 \%$ (25 patients). Of these, $12(48 \%)$ patients had intermittent claudication with nonpalpable distal pulses in $7(28 \%)$ patients. Women with PAD were older than men $(53.43 \pm 14.51$ years vs. $50.88 \pm 16.83$ years, $\mathrm{p}=0.5904)$.

Compared with patient without PAD, patients with PAD were older $(52.52 \pm$ 15.08 years vs. $46.14 \pm 14.89$ years), with a higher proportion of women (64\% vs $53.6 \%$ ) but the statistical differences were not significant (Table 1). Pre-dialysis and post-dialysis diastolic BP were significantly lower $(78.12 \pm 11.04 \mathrm{mmHg} v s$ $84.39 \pm 10.43 \mathrm{mmHg}, \mathrm{p}=0.0384$ and $75.44 \pm 10.18 \mathrm{mmHg}$ vs. $81.96 \pm 12.58$ $\mathrm{mmHg}, \mathrm{p}=0.0447$ respectively) in PAD patients. Significant differences were not found between the two groups of patients regarding hemodialysis duration, systolic BP, PP, MAP and BMI (Table 1).

Serum albumin, total cholesterol, HDL-cholesterol and LDL-cholesterol were almost similar in the two groups (Table 2). PAD patients had higher blood levels of iPTH, CRP and triglycerides, without significant differences ( $\mathrm{p}>0.05)$ (Table 2).

Table 2. Laboratory parameters among patients with PAD and without PAD.

\begin{tabular}{|c|c|c|c|}
\hline \multirow{2}{*}{ Laboratory parameters } & \multicolumn{3}{|c|}{ Peripheral arterial disease } \\
\hline & Yes $(\mathrm{n}=25)$ & No $(n=28)$ & $\mathrm{p}$-value \\
\hline Urea (mg/dL) & $1.21 \pm 0.47$ & $1.07 \pm 0.42$ & 0.2574 \\
\hline Creatinine (mg/L) & $84.47 \pm 50.91$ & $86.56 \pm 36.38$ & 0.8631 \\
\hline Sodium $(\mathrm{mEq} / \mathrm{L})$ & $138.72 \pm 3.69$ & $139.44 \pm 3.62$ & 0.4373 \\
\hline Potassium (mEq/L) & $4.79 \pm 0.92$ & $4.82 \pm 0.97$ & 0.9088 \\
\hline Calcium (mg/L) & $91.06 \pm 18.68$ & $92.99 \pm 8.23$ & 0.6221 \\
\hline Phosphate (mg/L) & $38.85 \pm 16.68$ & $44.16 \pm 14.84$ & 0.2256 \\
\hline iPTH(pg/mL) & $625.58 \pm 666.13$ & $599.23 \pm 425.26$ & 0.8629 \\
\hline Hemoglobin (g/dL) & $9.34 \pm 1.73$ & $9.35 \pm 1.74$ & 0.9834 \\
\hline Hematocrit (\%) & $29.06 \pm 5.34$ & $29.72 \pm 5.91$ & 0.6729 \\
\hline White blood cell counts (thousand/mL) & $5908.4 \pm 2041.94$ & $5497.14 \pm 1523.28$ & 0.4066 \\
\hline Albumin (g/L) & $40.70 \pm 5.49$ & $41.72 \pm 5.60$ & 0.5071 \\
\hline CRP (mg/L) & $16.78 \pm 33.31$ & $11.37 \pm 18.56$ & 0.4622 \\
\hline Fasting glucose $(\mathrm{g} / \mathrm{L})$ & $0.90 \pm 0.12$ & $0.91 \pm 0.10$ & 0.7422 \\
\hline Total cholesterol (g/L) & $1.97 \pm 0.45$ & $1.91 \pm 0.44$ & 0.6260 \\
\hline HDL-cholesterol (g/L) & $0.44 \pm 0.16$ & $0.47 \pm 0.10$ & 0.4116 \\
\hline LDL-cholesterol (g/L) & $1.34 \pm 0.44$ & $1.35 \pm 0.38$ & 0.9296 \\
\hline Triglycerides (g/L) & $1.22 \pm 0.99$ & $0.89 \pm 0.34$ & 0.1032 \\
\hline Total cholesterol/HDL ratio & $4.87 \pm 1.66$ & $4.27 \pm 1.31$ & 0.1481 \\
\hline URR (\%) & $74.51 \pm 9.0$ & $79.86 \pm 10.27$ & 0.0506 \\
\hline $\mathrm{Kt} / \mathrm{V}$ & $1.46 \pm 0.47$ & $1.68 \pm 0.63$ & 0.1598 \\
\hline
\end{tabular}

iPTH: intact parathyroid hormone; URR: urea reduction ratio. Creatinine $(\mathrm{mg} \times 8.8=\mu \mathrm{mol} / \mathrm{L})$. 


\section{Discussion}

In this study, PAD prevalence was $47.16 \%$. This was higher than those reported by other authors [5] [13] [14] [15] especially when we compared some risk factors like age, diabetes mellitus and smoking (Table 3). PAD prevalence in hemodialysis patients varies from $17 \%$ to $48 \%$ [1]. This large variability can be partly explained by the diagnostic criteria of PAD, which differ from one study to another. In some studies [14] [15], PAD was diagnosed at a clinical stage of the disease, based on data from patients' medical records (presence or history of intermittent claudication, gangrene, history of revascularization, or limb amputation). However, $40 \%$ of PAD patients are asymptomatic [16]. In other studies, such as ours [5] [12] [17], PAD diagnosis was made at a subclinical stage by measuring the ABI. But in CKD, diabetes, or in elderly subjects, the presence of mediacalcosis resulted in abnormally normal or high ABI. Hence, the calculation of toe-brachial index (TBI) was combined with $\mathrm{ABI}$ in some studies to minimize this bias [13] [18] (Table 3): the toe blood vessels are less prone to mediacalosis-related stiffening.

On the other hand, ABI measurement protocols vary dependent on studies, making it difficult to compare results. For the calculation of ABI, the lowest, highest or average systolic BP of the ankle can be used [3]. Using the lowest systolic pressure in lower limb, as in our study, or the mean systolic BP of the posterior tibial arteries, allows to increase the sensitivity and the reproducibility of the measurements but overestimates the severity of PAD in asymptomatic patients [3].

Age, hypertension, diabetes mellitus, smoking and dyslipidemia are known risk factors for PAD [12] [19]. Among those risk factors, diabetes mellitus and smoking have been identified as the most potent [16]. In our study, PAD subjects were on average older $(52.52 \pm 15.08$ years vs $46.14 \pm 14.89)$ but diabetes prevalence was low (4\%). As reported by Ono et al. [5], we found significant lower diastolic BP in PAD patients.

Table 3. Prevalence of PAD according to some studies.

\begin{tabular}{|c|c|c|c|c|c|c|}
\hline Authors & PAD assessment & PAD (\%) & Mean age (years) & HTN (\%) & Diabetes (\%) & Smokers (\%) \\
\hline Our study, 2012 & $\mathrm{ABI}$ & 47.1 & $49.15 \pm 15.18$ & 83 & 4 & 20.75 \\
\hline Ohtake et al. [18], 2011 & ABI/TBI & 47.2 & $67.8 \pm 12.2$ & 95.8 & 40 & 14.4 \\
\hline Adragao et al. [17], 2012 & $\mathrm{ABI}$ & 41 & $65.6 \pm 15$ & - & 20 & 22 \\
\hline Chen et al. [12], 2016 & $\mathrm{ABI}$ & $18.6 / 52.8^{*}$ & 59.3 & 91.3 & 58.2 & 19.9 \\
\hline Matsuzawa et al. [13], 2015 & $\mathrm{ABI} / \mathrm{TBI}$ & 38.1 & $66 \pm 11$ & - & 48.6 & 57.6 \\
\hline Ono et al. [5], 2003 & ABI & 16.5 & $60.6 \pm 12.5$ & 79 & 33.8 & 41.4 \\
\hline O'Hare et al. [14], 2002 & Symptomatic disease ${ }^{\star *}$ & 24 & $60 \pm 16$ & - & 43 & 47 \\
\hline Sebastianski et al. [15], 2014 & Symptomatic disease ${ }^{\star \star}$ & 19.1 & $60.3 \pm 15.6$ & 87.2 & 51.4 & 58.4 \\
\hline
\end{tabular}

ABI: ankle-brachial index; HTN: hypertension; PAD: peripheral arterial disease; TBI: toe-brachial index. ${ }^{*}$ African-americans, ${ }^{* *}$ : claudication symptoms, absent foot pulses, gangrene, previous vascular intervention or previous amputation due to vascular disease. 
For dyslipidemia, the lipid fractions associated with PAD differ from one study to another. In some reports, high LDL cholesterol levels [13] or low HDL cholesterol levels [8] [13] were the most significant fractions, while in another [14], high total cholesterol and high triglycerides levels, identified in the univariate analysis were not confirmed in the multivariate analysis. Thus, current data support the total cholesterol/HDL cholesterol ratio that was most correlated with PAD in the general population [19]. Like other authors [11] [17] [20], we did not find significant correlation between PAD and blood levels of total cholesterol, HDL cholesterol, LDL cholesterol, triglycerides or iPTH.

We observed a higher prevalence of PAD in women, which is consistent with the literature data [12] [19]. In developing countries, PAD tends to be more frequent among women in the general population, while in developed countries, the prevalence of PAD seemed to be similar between men and women [19].

Inflammation plays an important role in the occurrence of PAD [12] [19]. In our study, both CRP levels and white blood cell counts were higher in the PAD-patients group, but without significant difference.

Other reasons could also explain this high prevalence. Apart from traditional CVRF, PAD is associated with non-traditional CVRF such as fibrinogen, myeloperoxidase, glycated hemoglobin, insulin resistance and alkaline phosphatase [12]. These new CVRF are common in chronic renal failure patients and have not been studied in this work. In addition, black subjects have a higher PAD prevalence compared to other ethnic groups [12] [19] [21]. For African-Americans, poor access to health care services due to low socio-economic status, poor quality of life and genetic factors could account for the high morbidity. In sub-Saharan Africa, difficulty for populations to access healthcare services due to the lack of sufficient human resources and limitation of the technical healthcare platforms is a reality.

PAD is a powerful predictor of cardiovascular and global mortality in hemodialysis patients [5]. Diagnosing it earlier could be integrated into strategies for preventing cardiovascular and global morbidity and mortality in this population by establishing therapeutic means such as smoking cessation, regular physical activity practice by hemodialysis patients with a good tolerance to efforts, and by initiating drug therapy with statins and/or antiplatelet agents (aspirin, clopidogrel) [1] [16]. In patients with end stage chronic kidney disease (CKD), screening for PAD is recommended at the initiation of dialysis [1].

\section{Conclusion}

In the present study we found a high PAD prevalence amounting to $47.16 \%$ with more than half of patients (52\%) who were clinically asymptomatic. Also, screening for PAD should be systematic in groups of patients at high cardiovascular risk as in hemodialysis patients. This study had several limitations: a relatively small number of patients, the use of the smallest ankle systolic BP for the calculation of $\mathrm{ABI}$ and the fact that we did not study non-traditional cardiovascular risk factors. 


\section{Conflicts of Interest}

The authors declare no conflicts of interest regarding the publication of this paper.

\section{References}

[1] Herzog, C., Asinger, R., Berger, A., Charytan, D., Díez, J., Hart, R., et al. (2011) Cardiovascular Disease in Chronic Kidney Disease. A Clinical Update from Kidney Disease: Improving Global Outcomes (KDIGO). Kidney International, 80, 572-586. https://doi.org/10.1038/ki.2011.223

[2] Tranche-Iparraguirre, S., Marín-Iranzo, R., Sanmamed, RF., Riesgo-García, A., Hevia-Rodríguez, E. and García-Casas, J.B. (2012) Peripheral Arterial Disease and Kidney Failure: A Frequent Association. Revista Nefrologia, 32, 313-320.

[3] Ko, S.H. and Bandyk, D.F. (2013) Interpretation and Significance of Ankle-Brachial Systolic Pressure Index. Seminars in Vascular Surgery, 26, 86-94. https://doi.org/10.1053/j.semvascsurg.2014.01.002

[4] Lahoz, C., Barrionuevo, M., García-Fernández, T., Vicente, I., García-Iglesias, M.F. and Mostaza, J.M. (2014) Cardiovascular Morbidity-Mortality Associated to Ankle-Brachial Index in the General Population. Revista clínica Española, 214, 1-7. https://doi.org/10.1016/j.rce.2013.08.008

[5] Ono, K. (2003) Ankle-Brachial Blood Pressure Index Predicts All-Cause and Cardiovascular Mortality in Hemodialysis Patients. Journal of the American Society of Nephrology, 14, 1591-1598. https://doi.org/10.1097/01.ASN.0000065547.98258.3D

[6] Liew, Y.P., Bartholomew, J.R., Demirjian, S., Michaels, J. and Schreiber, M.J. (2008) Combined Effect of Chronic Kidney Disease and Peripheral Arterial Disease on All-Cause Mortality in a High-Risk Population. Clinical Journal of the American Society of Nephrology, 3, 1084-1089. https://doi.org/10.2215/CJN.04411007

[7] Jimenez, Z.N.C., Pereira, B.J., Romão, J.E., Makida, S.C. da S., Abensur, H., Moyses, R.M.A., et al. (2012) Ankle-Brachial Index: A Simple Way to Predict Mortality among Patients on Hemodialysis-A Prospective Study. PLoS ONE, 7, e42290. https://doi.org/10.1371/journal.pone.0042290

[8] Chen, J., Mohler, E.R., Xie, D., Shlipak, M.G., Townsend, R.R., Appel, L.J., et al. (2012) Risk Factors for Peripheral Arterial Disease among Patients with Chronic Kidney Disease. The American Journal of Cardiology, 110, 136-141. https://doi.org/10.1016/j.amjcard.2012.02.061

[9] National Kidney Foundation/KDOQI (2006) Clinical Practice Guidelines for Hemodialysis Adequacy, Update 2006. American Journal of Kidney Diseases, 48, S28-S32. https://doi.org/10.1053/j.ajkd.2006.05.016

[10] Chen, S.C., Liu, W.C., Chang, J.M., Huang, J.C., Yang, T.K., Chen, H.C., et al. (2012) Decrease in Ankle-Brachial Index Over Time and Cardiovascular Outcomes in Patients with Hemodialysis. The American Journal of the Medical Sciences, 344, 457-461. https://doi.org/10.1097/MAJ.0b013e31825141bf

[11] Tanaka, M., Ishii, H., Aoyama, T., Takahashi, H., Toriyama, T., Kasuga, H., et al. (2011) Ankle Brachial Pressure Index but Not Brachial-Ankle Pulse Wave Velocity Is a Strong Predictor of Systemic Atherosclerotic Morbidity and Mortality in $\mathrm{Pa}$ tients on Maintenance Hemodialysis. Atherosclerosis, 219, 643-647.

https://doi.org/10.1016/j.atherosclerosis.2011.09.037

[12] Chen, J., Mohler, E.R., Xie, D., Shlipak, M., Townsend, R.R., Appel, L.J., et al. (2016) Traditional and Non-Traditional Risk Factors for Incident Peripheral Arterial Dis- 
ease among Patients with Chronic Kidney Disease. Nephrology Dialysis Transplantation, 31, 1145-1151. https://doi.org/10.1093/ndt/gfv418

[13] Matsuzawa, R., Aoyama, N. and Yoshida, A. (2015) Clinical Characteristics of Patients on Hemodialysis with Peripheral Arterial Disease. Angiology, 66, 911-917. https://doi.org/10.1177\%2F0003319715572678

[14] O’Hare, A.M., Hsu, C.Y., Bacchetti, P. and Johansen, K.L. (2002) Peripheral Vascular Disease Risk Factors among Patients Undergoing Hemodialysis. Journal of the American Society of Nephrology, 13, 497-503. https://doi.org/10.1681/ASN.V132497

[15] Sebastianski, M., Tonelli, M. and Tsuyuki, R.T. (2015) Ethnic Differences in Prevalence of Peripheral Artery Disease in Patients Undergoing Hemodialysis. Journal of Racial and Ethnic Health Disparities, 2, 275-279.

https://doi.org/10.1007/s40615-014-0066-7

[16] Hennion, D.R. and Siano, K.A. (2013) Diagnosis and Treatment of Peripheral Arterial Disease. American Family Physician, 88, 306-310.

[17] Adragao, T., Pires, A., Branco, P., Castro, R., Oliveira, A., Nogueira, C., et al. (2012) Ankle-Brachial Index, Vascular Calcifications and Mortality in Dialysis Patients. Nephrology Dialysis Transplantion, 27, 318-325. https://doi.org/10.1093/ndt/gfr233

[18] Ohtake, T., Oka, M., Ikee, R., Mochida, Y., Ishioka, K., Moriya, H., et al. (2011) Impact of Lower Limbs' Arterial Calcification on the Prevalence and Severity of PAD in Patients on Hemodialysis. Journal of Vascular Surgery, 53, 676-683. https://doi.org/10.1016/j.jvs.2010.09.070

[19] Fowkes, F.G.R., Aboyans, V., Fowkes, F.J.I., McDermott, M.M., Sampson, U.K.A. and Criqui, M.H. (2017) Peripheral Artery Disease: Epidemiology and Global Perspectives. Nature Reviews Cardiology, 14, 156-170. https://doi.org/10.1038/nrcardio.2016.179

[20] de Vinuesa, S.G., Ortega, M., Martinez, P., Goicoechea, M., Campdera, F.G. and Luño, J. (2005) Subclinical Peripheral Arterial Disease in Patients with Chronic Kidney Disease: Prevalence and Related Risk Factors. Kidney International, 67, S44-S47. https://doi.org/10.1111/j.1523-1755.2005.09310.x

[21] Vitalis, A., Lip, G.Y.H., Kay, M., Vohra, R.K. and Shantsila, A. (2017) Ethnic Differences in the Prevalence of Peripheral Arterial Disease: A Systematic Review and Meta-Analysis. Expert Review of Cardiovascular Therapy Expert, 15, 327-338. https://doi.org/10.1080/14779072.2017.1305890 